\title{
Polyhydroxyalkanoate (PHA) production from sludge and municipal wastewater treatment
}

\author{
F. Morgan-Sagastume, F. Valentino, M. Hjort, D. Cirne, L. Karabegovic, \\ F. Gerardin, P. Johansson, A. Karlsson, P. Magnusson, T. Alexandersson, \\ S. Bengtsson, M. Majone and A. Werker
}

\begin{abstract}
Polyhydroxyalkanoates (PHAS) are biodegradable polyesters with comparable properties to some petroleum-based polyolefins. PHA production can be achieved in open, mixed microbial cultures and thereby coupled to wastewater and solid residual treatment. In this context, waste organic matter is utilised as a carbon source in activated sludge biological treatment for biopolymer synthesis. Within the EU project Routes, the feasibility of PHA production has been evaluated in processes for sludge treatment and volatile fatty acid (VFA) production and municipal wastewater treatment. This PHA production process is being investigated in four units: (i) wastewater treatment with enrichment and production of a functional biomass sustaining PHA storage capacity, (ii) acidogenic fermentation of sludge for VFA production, (iii) PHA accumulation from VFA-rich streams, and (iv) PHA recovery and characterisation. Laboratory- and pilot-scale studies demonstrated the feasibility of municipal wastewater and solid waste treatment alongside production of PHA-rich biomass. The PHA storage capacity of biomass selected under feast-famine with municipal wastewater has been increased up to $34 \%$ (g PHA g VSS ${ }^{-1}$ ) in batch accumulations with acetate during $20 \mathrm{~h}$. VFAs obtained from waste activated sludge fermentation were found to be a suitable feedstock for PHA production.

Key words | municipal wastewater treatment, pilot, polyhydroxyalkanoates (PHAs), volatile fatty acids (VFAs)

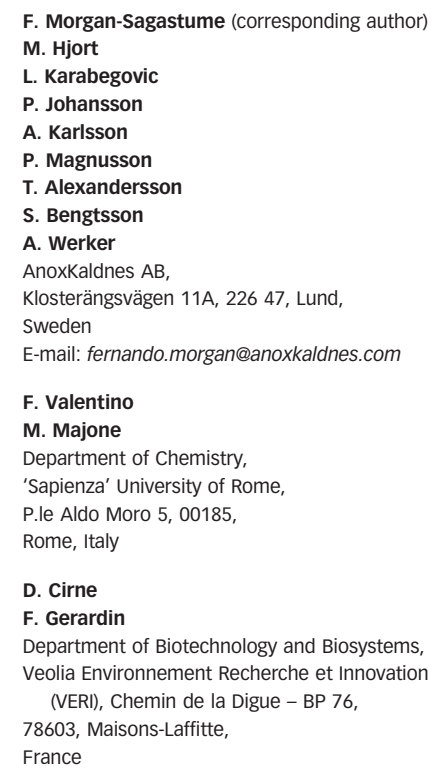

\section{$\overline{\text { INTRODUCTION }}$}

A shift in mindset for the management of wastes is underway. Wastewater treatment plants long considered as endof-pipe processes are increasingly considered within biorefinery frameworks in efforts to move towards a bio-based society (De Vegt et al. 20I2). In a wastewater biorefinery, wastewater organics and inorganics represent raw resources from which renewable products (energy, minerals and green chemicals) can be obtained as part of waste management. Polyhydroxyalkanoates (PHAs) are completely biodegradable polymers that can be produced in open, mixed microbial cultures as part of biological treatment of municipal and industrial wastes and residuals (Serafim et al. 2008). Hence, PHAs are potential by-products from wastewater bio-refining (Dias et al. 2006), whose thermoplastic properties and flexible applicability make them key ingredients to biodegradable plastics (Philip et al. 2007).
PHA production involving microbial cultures treating wastewater addresses strategies to decrease production costs of conventional pure-culture PHA processes. PHA production further valorises wastewater treatment by recycling and channelling carbon towards products and reducing sludge production. PHA production with wastewater treatment implies selectively growing/enriching PHA-storing bacteria in activated sludge based on engineered environments exerting dynamic conditions with respect to substrate feeding (i.e., alternating conditions of carbon availability and unavailability) (Dionisi et al. 2004) or electron acceptor availability (aerobic vs anaerobic) (Satoh et al. I998; Bengtsson et al. 2008a). Substrate aerobic dynamic feeding (ADF) or feast-famine has been the commonly applied enrichment approach (Dias et al. 2006). The main substrates used for the selective growth of PHA-storing 
organisms and PHA production have been volatile fatty acids (VFAs) since VFAs are efficiently converted into PHAs, whereas carbohydrates are preferably stored as polysaccharides (Dircks et al. 200I). Until now, PHA production together with wastewater treatment has been preferentially investigated in a three-stage process (Serafim et al. 2008): (i) wastewater acidogenic fermentation for the production of a VFA-rich stream, (ii) ADF enrichment of PHA-storing organisms based on a VFA-rich stream, and (iii) PHA accumulation using the same VFA-rich stream as for enrichment, and a final stage for PHA recovery and purification. PHA production from different industrial and solids streams has been demonstrated under such conditions (e.g., Dionisi et al. 2005; Coats et al. 2007; Bengtsson et al. 2008b). Although readily biodegradable carbohydrates combined with VFAs have also been shown to support PHA production in open systems (Voltolini 2009), limited knowledge exists on the applicability of broadcomposition feedstocks, such as municipal wastewater, in PHA production (Takabatake et al. 2002; Bengtsson et al. 20I2).

As part of the European Union project Routes (Braguglia et al. 20I2), the technical feasibility of PHA production integrated to municipal waste management is being evaluated. Selective growth of PHA-storing organisms is being considered based not on VFAs from a VFA-rich stream but on the readily biodegradable chemical oxygen demand
(COD) of municipal wastewater, a strength-variable and sometimes VFA-poor stream. For PHA production, a VFArich stream is sourced from the acidogenic fermentation of primary sludge. In the present work, the feasibility of producing a functional biomass with PHA-storing ability is demonstrated at laboratory- and pilot-scales while providing some level of municipal wastewater treatment. Furthermore, PHA production from VFAs obtained from waste activated sludge (WAS) acidogenic fermentation is benchmarked with biomass with PHA storage capacity. The piloting system reported herein constitutes, to the best knowledge of the authors, the first pilot-scale system treating municipal wastewater and producing biomass with enhanced PHA storage capacity.

\section{METHODS}

PHA production together with municipal wastewater and sludge treatment is investigated as a four-stage process: (i) removal of readily biodegradable carbon from wastewater coupled to the selective growth of biomass with PHA storage capacity, (ii) sludge acidogenic fermentation for the production of a VFA-rich liquid stream, (iii) PHA accumulation from the VFA-rich liquid stream using enriched biomass from step (i), and (iv) PHA recovery and characterisation (Figure 1).

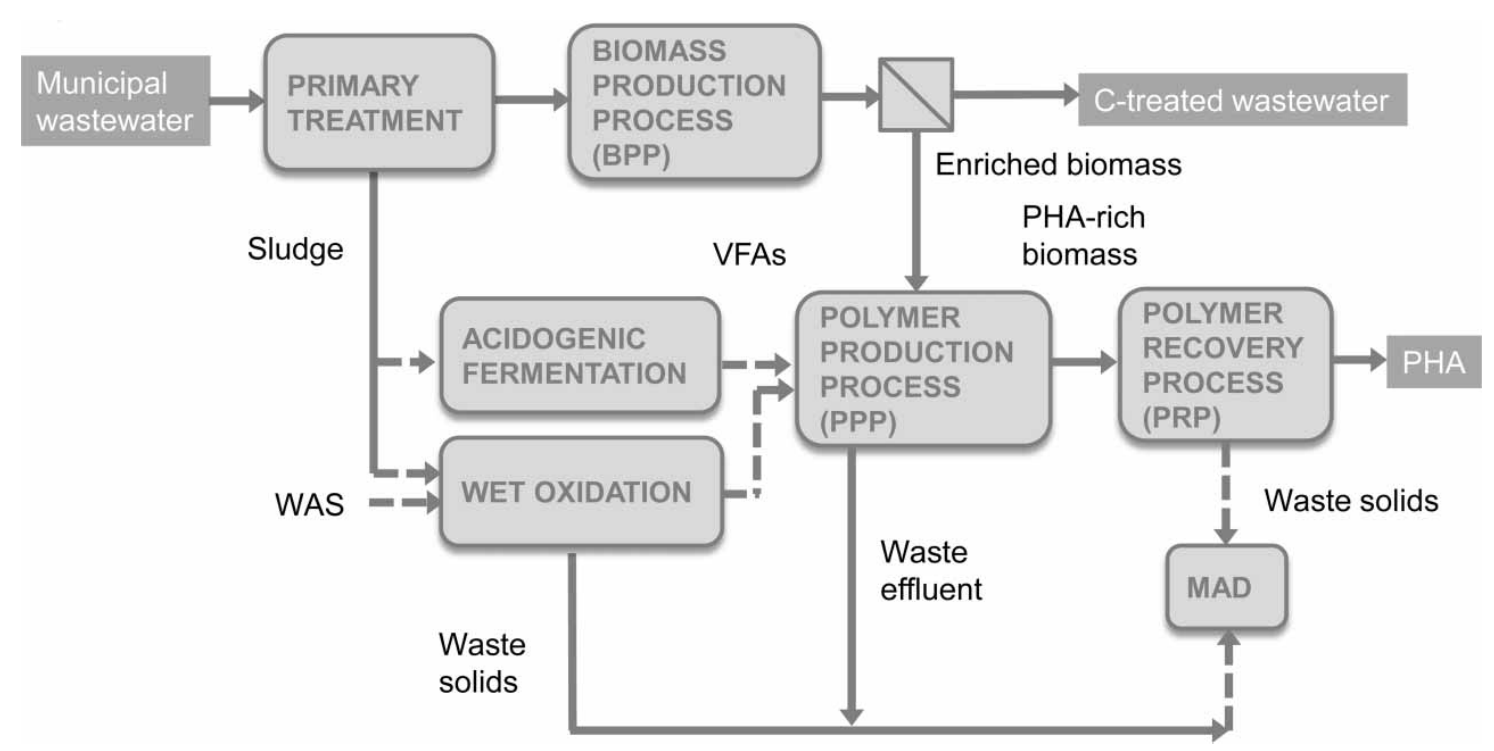

Figure 1 | Schematic process flow diagram of municipal wastewater and sludge treatment in conjunction with PHA production under study in the project Routes (MAD = mesophilic anaerobic digestion). Laboratory-scale studies are conducted on BPP, PPP and PRP (La Sapienza University of Rome/AnoxKaldnes), advanced/ primary treatment and sludge fermentation (Italian Water Research Institute IRSA-CNR). Pilot-scale studies are conducted on fermentation, BPP, PPP and PRP (AnoxKaldnes/Veolia) and sludge wet oxidation for producing a VFA-rich liquid stream (3VGreen Eagle). Results from WAS fermentation, BPP, PPP are reported here. 


\section{Laboratory-scale experiments}

A one-litre sequencing batch reactor (SBR) was used to select and produce biomass with increased PHA-storing capacity. The SBR was inoculated with activated sludge (Roma North wastewater treatment plant (WWTP)) and operated for 31 days: organic loading rate $(\mathrm{OLR})=3.1 \mathrm{~g}$ COD L $\mathrm{d}^{-1}$, hydraulic retention time $(\mathrm{HRT})=2.1 \mathrm{~h}$, solids retention time $(\mathrm{SRT})=1.5 \mathrm{~d}$, cycle length $=1.5 \mathrm{~h}$, temperature $(T)=22.5^{\circ} \mathrm{C}$ (controlled by a thermal jacket), and $\mathrm{pH}$ of 8.0 (uncontrolled). The SBR operating cycle included: biomass withdrawal $(0.5 \mathrm{~min})$, settling $(30 \mathrm{~min})$, supernatant withdrawal $(3 \mathrm{~min})$, feeding $(3 \mathrm{~min})$, and reaction phase $(53.5 \mathrm{~min})$. Aeration (membrane compressors) and stirring $(100 \mathrm{rpm})$ were provided during the reaction phase, and stirring during biomass withdrawal. Synthetic municipal wastewater fed to the SBR contained acetic acid (11\% on a COD basis; SAFC W30, 240-6-K), yeast extract (13\%; Sigma-Aldrich Y1626), glucose (27\%; Sigma-Aldrich G5767), starch (25\%; Sigma-Aldrich S9765) and peptone (24\%; Merck KGaA 1.07213), with a total COD concentration of $275 \mathrm{mg} \mathrm{L}^{-1}$, and $\mathrm{NH}_{4} \mathrm{Cl}$ (Sigma-Aldrich 09718; $35 \mathrm{mg} \mathrm{NH}{ }_{4}^{+}-\mathrm{N} \mathrm{L}^{-1}$ ) and $\mathrm{KH}_{2} \mathrm{PO}_{4}$ (Riedel-de Haën 33270; $3 \mathrm{mg} \mathrm{P}-\mathrm{PO}_{4}^{3-} \mathrm{L}^{-1}$ ). The synthetic wastewater mimicked the soluble and biodegradable organic content of mediumstrength municipal wastewater after primary treatment. A pseudo-steady state was considered reached when the feast phase length, based on dissolved oxygen (DO) consumption, remained within 5\% deviation from average values for at least five consecutive days.

A PHA-accumulation potential test $(0.5-\mathrm{L}$ reactor; $0.5 \mathrm{~g}$ volatile suspended solids (VSS) $\mathrm{L}^{-1} ; 22.5^{\circ} \mathrm{C}$ ) was conducted with SBR biomass in a fed-batch laboratory-scale reactor under aerobic conditions $\left(\mathrm{DO}=2-8 \mathrm{mg} \mathrm{L}^{-1}\right.$ via air pump and glass diffuser), $\mathrm{N}$ excess $\left(100 \mathrm{mg} \mathrm{NH}_{4}^{+}-\mathrm{N} \mathrm{L}^{-1}\right.$ at the beginning of the tests), magnetic stirring (300 rpm), $T$ control (water jackets connected to water bath), $\mathrm{pH}$ manual control at 8.0 via $0.8 \mathrm{M} \mathrm{H}_{2} \mathrm{SO}_{4}$ addition. A mixture of acetic and propionic acids ( 85 and 15\% COD basis, respectively) was spiked twice during the accumulation (6-8 h), targeting a concentration of $1.0 \mathrm{~g} \mathrm{COD}_{\mathrm{VFA}} \mathrm{L}^{-1}$ in the reactor for the first spike. The second 1-mL spike ensured continued VFA availability and PHA storage. Mixed liquor was sampled regularly for analyses (COD, VFA, storage compounds, and $\mathrm{NH}_{4}^{+}-\mathrm{N}$ ).

Parallel, fed-batch PHA accumulations were also conducted with biomass enriched using fermented cheese whey permeate in a pilot-scale, feast-famine $\operatorname{SBR}(V=$ $400 \mathrm{~L}, \mathrm{OLR}=2.0 \mathrm{~g} \mathrm{COD} \mathrm{L}^{-1} \mathrm{~d}^{-1}, \mathrm{SRT}=4$ days, $\mathrm{HRT}=1$ ).
Acetate and permeate from fermented WAS were used as substrates. The accumulation with fermented WAS provided for a performance benchmark using a well-enriched biomass. These accumulations were conducted aerobically $\left(\mathrm{DO}=1-4.5 \mathrm{mg} \mathrm{L}^{-1}\right)$ in reactors with $0.5-\mathrm{L}$ working volume at $T=30{ }^{\circ} \mathrm{C}$ and $\mathrm{pH} \sim 8.5$, similar to those of the pilot SBR. The mixed liquor was first aerated for $20 \mathrm{~min}$ until constant $\mathrm{pH}$ and DO levels were achieved. Substrate feed aliquots were dosed via a diaphragm pump (Grundfos DME) targeting a maximum respiration response based on feed-on-demand respirometric control (Werker et al. 20п). Mixed liquor was sampled during the accumulations for PHA, COD ${ }_{\text {sol }}(1.6 \mu \mathrm{m}$ filter), $\mathrm{N}$ and $\mathrm{P}$ analyses.

\section{Pilot-scale experiments}

Pilot-scale testing comprised three units located at the Brussels North WWTP (Aquiris, Belgium): (i) WAS acidogenic fermenter, (ii) biomass production process (BPP), and (iii) polymer production or accumulation process (PAP), designed based on the production of $1 \mathrm{~kg}$ PHA. The pilot units, in comparison to the laboratory equipment, consisted of larger volume reactors $(500-1,000 \mathrm{~L})$ and process units operating with actual WAS and municipal wastewater under regular process variations typical of a full-scale WWTP.

The fermentation unit includes an anaerobic batch reactor $(V=1,000 \mathrm{~L})$ and a centrifugation unit. Five fermentation batches at $42{ }^{\circ} \mathrm{C}$ with mixing and without $\mathrm{pH}$ control $(\mathrm{pH}=5.5-6.5)$ were conducted with thickened WAS (3-5\% w/w TS, Brussels North, SRT $=14 \mathrm{~d})$. The centrifugation unit used for solids/liquid separation comprises a cylindro-conical bowl-scroll centrifuge (Andritz EX-SC8000 ) connected to a conditioning/delivery unit of cationic polyacrylamide (granular FO4800SH, SNF/FLOERGER), used as coagulant/flocculant.

The BPP includes a wastewater delivery line with a drum filter for solids/fibre removal (mesh of $130-600 \mu \mathrm{m}$ ), a feeding tank $(V=500 \mathrm{~L})$ and an aerobic feast-famine SBR $(V=500 \mathrm{~L})$. Screened municipal wastewater after fat/ sand removal is fed into BPP. The SBR treating the filtered wastewater operated under a feast-to-aerobic-cycle length ratio of 0.15 at high OLRs $\left(3 \mathrm{~g} \mathrm{COD} \mathrm{L}^{-1} \mathrm{~d}^{-1}, 1.5 \mathrm{~g}\right.$ COD g $\mathrm{VSS}^{-1} \mathrm{~d}^{-1}$ ) and short retention times (HRT $=3 \mathrm{~h}$ and SRT $=1-2 \mathrm{~d}$ ), with 12 cycles per day including feeding (aeration and mixing), reaction (aeration and mixing), settling and effluent discharge under quiescent conditions, and further reaction (aeration mixing). Excess sludge targeting an SRT was wasted once per day in a single cycle. The filtered wastewater feeding the SBR was characterised by 
200-700 mg COD L ${ }^{-1}, 30-270 \mathrm{mg} \mathrm{COD}_{\text {sol }} \mathrm{L}^{-1}, 18-65 \mathrm{mg}$ $\mathrm{COD}_{\mathrm{VFA}} \mathrm{L}^{-1}\left(17-60 \%\right.$ of $\left.\mathrm{COD}_{\text {sol }}\right) \quad 60-450 \mathrm{mg}$ total suspended solids (TSS) $\mathrm{L}^{-1}, 30-270 \mathrm{mg}$ VSS $\mathrm{L}^{-1}, 19-76 \mathrm{mg} \mathrm{N}$

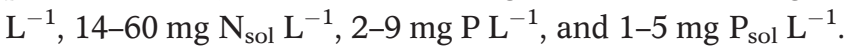

The PAP includes an accumulation reactor $(V=$ $500 \mathrm{~L}$ ) and sludge thickening units (settler and diffused air floatation) in one container, and a dewatering centrifuge and an oven in a second container. The PHAstorage capacity of BPP biomass was characterised based on triplicate fed-batch PHA accumulations (20$30 \mathrm{~h})$ with large acetate additions $\left(1,000 \mathrm{mg} \mathrm{COD} \mathrm{L}^{-1}\right.$ in reactor per pulse) and with small acetate additions using feed-on-demand respirometric control (Werker et al. 20II).

TSS and VSS, PHA, and VFAs were monitored as reported elsewhere (Bengtsson et al. 2008b; Valentino et al. 20I3). PHA content in the pilot-scale biomass was determined based on thermal gravimetric analysis (Q500 TA Instruments; Werker et al. 2012), Briefly, dried PHArich biomass ( 2 and $10 \mathrm{mg}$ ) was heated in $\mathrm{N}_{2}$ up to $550{ }^{\circ} \mathrm{C}$. First, $T$ was raised to $105^{\circ} \mathrm{C}\left(10^{\circ} \mathrm{C} / \mathrm{min}\right.$ and held for $10 \mathrm{~min}$ ) and moisture loss was assessed. Then, $T$ was raised to $550^{\circ} \mathrm{C}\left(10^{\circ} \mathrm{C} / \mathrm{min}\right)$ and weight loss assessed. At $550{ }^{\circ} \mathrm{C}$, the oven atmosphere was changed from $\mathrm{N}_{2}$ to air. Ash content was assessed based on weight loss at $550{ }^{\circ} \mathrm{C}$ in air for $30 \mathrm{~min}$, and weight losses and weight loss rate changes as a function of $T$ were analysed. For PHA contents greater than $5 \%$, a well-defined peak of weight loss is resolvable.

\section{RESULTS AND DISCUSSION}

\section{BPP municipal wastewater treatment and enrichment of PHA-storing biomass}

In the laboratory-scale SBR, the length of the feast, corresponding to the depletion of easily biodegradable substrate after feeding in each cycle, was indicated by a sudden DO increase (Figure 2(a)). A relatively constant feast was achieved after 4-5 SRTs, in which the average substrate depletion time was $3.6 \mathrm{~min}$ and the feast length was less than $7 \%$ of the total aerobic time. In the traditional and well-documented enrichment with VFAs or VFA-rich streams (Dionisi et al. 2004; Albuquerque et al. 2007; Jiang et al. 2012), a short feast in SBRs $(<20 \%$ of the cycle length) has resulted in a strong selective pressure and in the enrichment of biomass with increased storage capacity. On the other hand, the slow DO increase after the removal
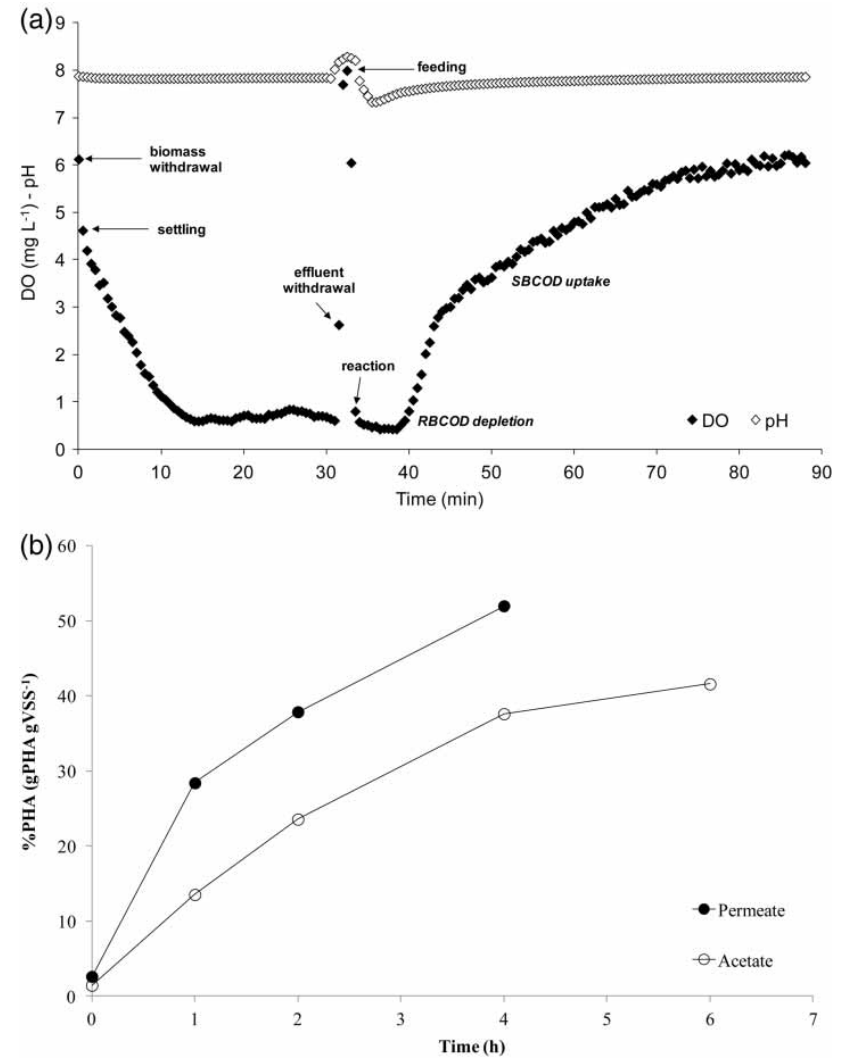

Figure 2 | Laboratory-scale experimental results. (a) Typical DO and pH profiles during an $\mathrm{SBR}$ cycle $(\mathrm{RBCOD}=$ readily biodegradable $\mathrm{COD} ; \mathrm{SBCOD}=$ slowly biodegradable COD; arrows indicate the start of each phase in the SBR cycle), and (b) biomass PHA content during a fed-batch PHA accumulation with the liquid fraction of fermented WAS from the pilot plant and biomass enriched with fermented cheese whey permeate.

of the easily biodegradable COD (Figure 2(a)) showed that the uptake of the slowly biodegradable COD fraction, estimated to correspond to $40-50 \%$ of the total soluble COD, occurred during the 'famine'. PHA accumulation was not observed during the uptake of this slowly degradable COD. The ability of the selected biomass to store poly(3-hydroxybutyrate-co-3-hydroxyvalerate) (PHBV) was reflected by a storage rate of $82 \mathrm{mg} \mathrm{COD}_{\mathrm{PHA}} \mathrm{g} \mathrm{COD}_{\mathrm{Xa}}^{-1} \mathrm{~h}^{-1}$ and yield of $0.18 \mathrm{~g} \mathrm{COD}_{\mathrm{PHA}} \mathrm{g} \mathrm{COD}^{-1}$ at the end of the feast (Table 1). The harvested SBR biomass was able to accumulate in 8 hours up to $13 \%$ (g PHA g VSS $^{-1}$ ) in batch accumulations with acetate and propionate as substrates.

The pilot-scale SBR (BPP) was operated for 7 months, after start-up and performance optimisation with respect to a decrease in the feast length and increase in biomass activity. The organic loadings to the SBR changed during the day based on the variations in the incoming wastewater organic levels, with higher loading occurring in the 
Table 1 | Main operating parameters (mean \pm standard deviation) measured in the labscale SBR fed with synthetic municipal wastewater. Active biomass, $X_{a}$, is defined as non-polymer biomass $\left(\mathrm{X}_{\mathrm{a}}=\mathrm{VSS}-\mathrm{PHA}\right)$; 3 - $\mathrm{HV}=3$-hydroxyvalerate

\begin{tabular}{|c|c|c|}
\hline Parameter & $\begin{array}{l}\text { End of } \\
\text { cycle }\end{array}$ & $\begin{array}{l}\text { End of } \\
\text { feast }\end{array}$ \\
\hline Active biomass $\left(\mathrm{X}_{\mathrm{a}}, \mathrm{mg} \mathrm{COD} \mathrm{L}^{-1}\right)$ & - & $3518 \pm 126$ \\
\hline PHBV (mg COD L $\left.{ }^{-1}\right)$ & $45 \pm 5$ & $62 \pm 9$ \\
\hline \% PHA (g PHA g VSS ${ }^{-1}$ ) & - & $1.7 \pm 0.2$ \\
\hline \% 3-HV (g 3-HV g PHBV ${ }^{-1}$ ) & $11 \pm 2$ & $8 \pm 1$ \\
\hline Substrate depletion time (min) & \multicolumn{2}{|c|}{$3.6 \pm 0.2$} \\
\hline $\begin{array}{l}\text { Specific substrate uptake rate } \\
\qquad\left(-\mathrm{r}_{\mathrm{S}}, \mathrm{mg} \text { COD g } \mathrm{COD}_{\mathrm{Xa}}^{-1} \mathrm{~h}^{-1}\right)\end{array}$ & \multicolumn{2}{|c|}{$446 \pm 23$} \\
\hline $\begin{array}{l}\text { Specific storage rate } \\
\qquad\left(\mathrm{r}_{\mathrm{PHA}}, \mathrm{mg} \mathrm{COD}_{\mathrm{PHA}} \mathrm{g}_{\left.\mathrm{COD}_{\mathrm{Xa}}^{-1} \mathrm{~h}^{-1}\right)}\right.\end{array}$ & \multicolumn{2}{|l|}{$82 \pm 26$} \\
\hline Storage yield (Y $\mathrm{Y}_{\mathrm{STO}}^{\text {feast }}$ g $\mathrm{COD}_{\mathrm{PHA}} \mathrm{g} \mathrm{COD}^{-1}$ ) & \multicolumn{2}{|c|}{$0.18 \pm 0.06$} \\
\hline
\end{tabular}

afternoon. Biomass production corresponded to $200-400 \mathrm{~g}$ $\mathrm{VSS} \mathrm{d}^{-1}$ with estimated observed biomass yields of 0.3 $0.4 \mathrm{~g} \mathrm{VSS} \mathrm{g} \mathrm{COD}^{-1}$. The two pilot PHA accumulation approaches with acetate indicated that the BPP biomass increased its storage capacity from 14\% (g PHA g VSS ${ }^{-1}$ ), corresponding to that of the activated sludge inoculum, up to $25 \%$ (g PHA $\mathrm{g} \mathrm{VSS}^{-1}$ ) in accumulations with large feeding and up to 34\% (g PHA g VSS ${ }^{-1}$ ) with feed-on-demand (Figure 3(a), Table 2).

Both biomasses from the laboratory-scale SBR fed with synthetic wastewater and pilot-scale SBR fed with filtered municipal wastewater showed an increase in PHA storage capacity. These results support earlier reports of activated sludge biomass with PHA storage capacity obtained with municipal wastewater as feed (Takabatake et al. 2002; Bengtsson et al. 20I2), and further demonstrate the feasibility of enriching and producing biomass with increased PHA storage capacity using a VFA-poor stream compared to conventional VFA-rich feast-famine approaches widely reported in the literature (e.g., Serafim et al. 2008; Jiang et al. 2012). The observed PHA accumulation potential of the biomass was lower than the $50 \%$ or higher reported for cultures enriched with VFA-rich streams. However, from a VFA-utilisation perspective, these results support the efficient potential utilisation of VFAs for PHA production. Strategies to augment the enrichment pressure should be further investigated. The biomass enriched and grown in the pilot-scale BPP displays relatively lower PHA accumulation kinetics than the biomass from the laboratory-scale SBR using a more stable synthetic feed.

In terms of wastewater treatment, in the laboratory-scale SBR, an average 90\% COD removal was achieved with
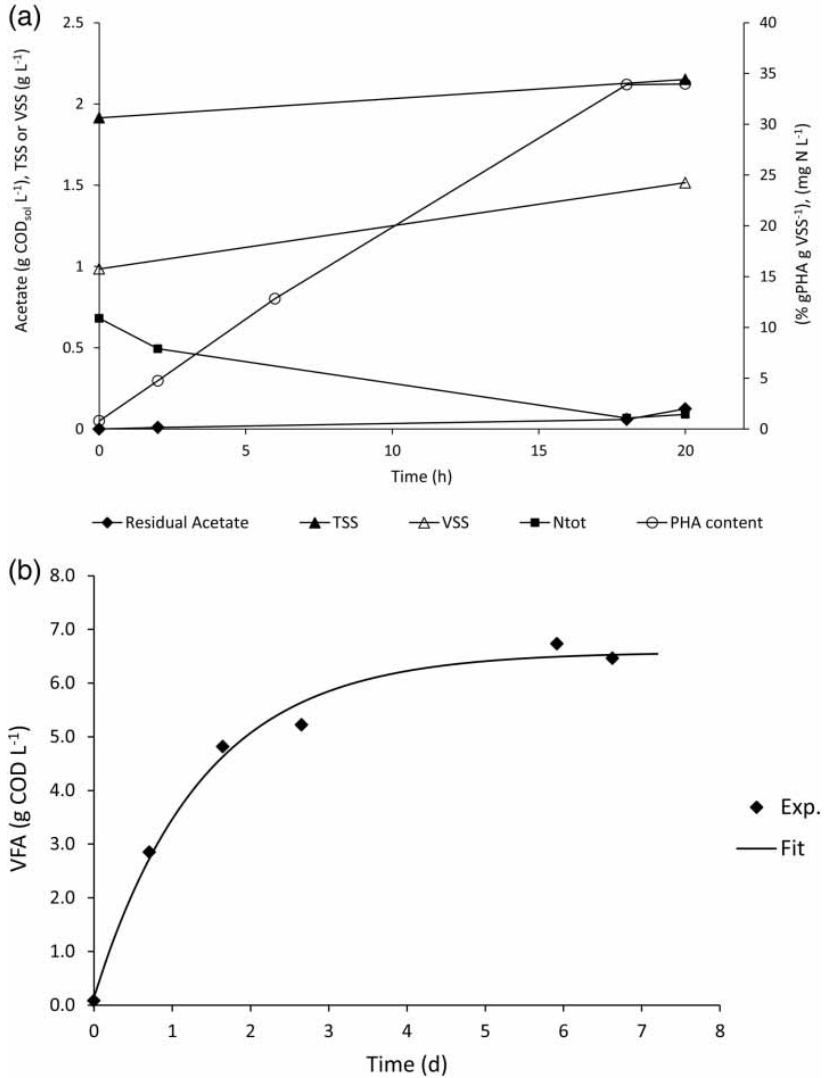

Figure 3 | Pilot-scale experimental results. (a) Typical profiles obtained during a feed-ondemand batch PHA accumulation in PAP using acetate as substrate, and (b) typical experimental and fitted VFA profiles during a batch acidogenic fermentation of WAS at $42{ }^{\circ} \mathrm{C}$

an effluent $\mathrm{COD}<30 \mathrm{mg} \mathrm{L}^{-1}$ and $\mathrm{TSS}<40 \mathrm{mg} \mathrm{L}^{-1}$. The pilot-scale SBR removed $70-80 \%$ of COD, $15-30 \%$ of $\mathrm{TN}$, and $30-60 \%$ of TP with respect to the incoming filtered wastewater. A post-treatment may be required for extended treatment, particularly for enhanced nutrient removal.

\section{Sludge as a source of VFAs for PHA production}

Acidogenic fermentation of WAS at $42{ }^{\circ} \mathrm{C}$ was feasible, achieving maximum VFA levels of $7.0 \pm 1.0 \mathrm{~g} \mathrm{COD}_{\mathrm{VFA}} \mathrm{L}^{-1}$ during $5.9 \pm 0.2$ days of batch fermentation (Figure 3(b)). VFA production yields corresponded to $27 \pm 3 \% \mathrm{~g}$ COD $\mathrm{VFA}$ g VS $_{\text {init. }}^{-1}\left(20 \pm 4 \%\right.$ g COD VFA $_{\text {g COD }}^{-1}$ init. $)$ with solids reduction of $35 \pm 7 \%$ (VS) and solubilisation of $29 \pm 2 \%\left(\mathrm{~g} \mathrm{COD}_{\text {sol }}\right.$ $\mathrm{g} \mathrm{VS}_{\text {init. }}^{-1}$. Of the final soluble COD, $90 \pm 10 \%$ (g COD $\mathrm{g} \mathrm{COD}_{\text {sol }}^{-1}$ ) corresponded to VFAs. The fermentation products were dominated by VFAs: 38\% acetic (COD basis), 18\% butyric, $14 \%$ propionic, $13 \%$ iso-valeric, $11 \%$ valeric, $5 \%$ isobutyric, and $1 \%$ caproic acids. Lactic acid levels were below $10 \mathrm{mg}$ COD $\mathrm{L}^{-1}$. Nutrient release yielded a final 
Table 2 | PHA accumulation performance in PAP of the biomass from BPP (pilot-scale) during different tests conducted at different times using two different accumulation approaches: feed spiking and feed-on-demand based on respirometry using acetic acid as substrate

\begin{tabular}{|c|c|c|c|c|}
\hline Parameter & Unit & Test 1 & Test 2 & Test 3 \\
\hline \multicolumn{5}{|l|}{ Large substrate spiking } \\
\hline Date & & 18.01.2012 & 31.01 .2012 & 28.02.2012 \\
\hline Accumulation time & $\mathrm{h}$ & 30 & 30 & 30 \\
\hline Maximum PHA content & g PHA g VSS $^{-1}$ & 0.19 & 0.20 & 0.25 \\
\hline $\mathrm{Y}_{\mathrm{PHA} / \mathrm{COD}}^{\mathrm{a}}$ & g COD g COD sol $^{-1}$ & 0.38 & 0.35 & 0.35 \\
\hline $\mathrm{Y}_{\mathrm{Xa} / \mathrm{COD}}^{\mathrm{a}}$ & g COD g COD sol $^{-1}$ & 0.30 & 0.21 & 0.30 \\
\hline \multicolumn{5}{|l|}{ Feed-on-demand } \\
\hline Date & & 22.05 .2012 & 06.06 .2012 & 11.07.2012 \\
\hline Accumulation time & $\mathrm{h}$ & 20 & 20 & 20 \\
\hline Maximum PHA content & g PHA g VSS ${ }^{-1}$ & 0.34 & 0.30 & 0.27 \\
\hline $\mathrm{Y}_{\mathrm{PHA} / \mathrm{COD}}^{\mathrm{a}}$ & g COD g COD sol $^{-1}$ & 0.20 & 0.28 & 0.30 \\
\hline $\mathrm{Y}_{\mathrm{Xa} / \mathrm{COD}}^{\mathrm{a}}$ & g COD g COD sol $^{-1}$ & 0.04 & 0.07 & 0.05 \\
\hline
\end{tabular}

$\mathrm{Y}=$ yield; ${ }^{\mathrm{a} C O D}$ conversions: $1 \mathrm{~g}$ acetic acid $=1.0667 \mathrm{~g}$ COD; $1 \mathrm{~g}$ poly-3-hydroxybutyrate $=1.67 \mathrm{~g}$ COD; $1 \mathrm{~g}$ VSS $=1.45 \mathrm{~g}$ COD; $1 \mathrm{~g} \mathrm{X}_{\mathrm{a}}=1.45 \mathrm{~g}$ COD, where $\mathrm{X}_{\mathrm{a}}$ corresponds to non-PHA VSS.

fermented liquor with an average $\mathrm{COD}_{\text {sol }}: \mathrm{N}: \mathrm{P}$ ratio of 100:12:7. After centrifugation of the fermented sludge, the fermented WAS centrate was characterised by TSS levels $\leq$ $1 \mathrm{~g} \mathrm{~L}^{-1}$ and a volumetric recovery of $70 \% \mathrm{v} / \mathrm{v}$ centrate/fermented sludge was preliminarily obtained.

The WAS fermentation performance obtained here is comparable or superior to that reported elsewhere for WAS or primary sludge/WAS mixtures, which indicates the high fermentability of the sludge from Brussels North WWTP without primary treatment. Ucisik \& Henze (2008) reported yields of $0.011-0.024 \mathrm{~g} \mathrm{COD}_{\mathrm{VFA}} \mathrm{g} \mathrm{VS}_{\text {init. }}^{-1}$ and $0.20-0.26 \mathrm{~g}$ $\mathrm{COD}_{\mathrm{VFA}} \mathrm{g} \mathrm{VS}_{\text {init. }}^{-1}$ from the batch fermentation (room $T, 5 \mathrm{~d}$ ) of WAS and primary sludge, respectively, from different Danish WWTPs (nutrient removal, SRTs $=20-36 \mathrm{~d}$ ). Also, yields of $0.06,0.11$ and $0.27 \mathrm{~g} \mathrm{COD}_{\mathrm{VFA}} \mathrm{g} \mathrm{VSS}^{-1}$ and COD solubilisations of 7, 21 and 19\% were reported from the semi-continuous fermentation $\left(35-37^{\circ} \mathrm{C}, \mathrm{SRT}=5 \mathrm{~d}, 8.5 \mathrm{~g}\right.$ $\mathrm{VSS} \mathrm{L}^{-1}$ ) of WAS, mixed primary/WAS, and primary sludge, respectively. Slightly lower yields $(0.18$ and $0.20 \mathrm{~g}$ $\mathrm{COD}_{\mathrm{VFA}} \mathrm{g} \mathrm{VSS}^{-1}$ ) were obtained at higher VSS levels (30 g $\mathrm{VSS} \mathrm{L}^{-1}$ ) from the fermentation of primary sludge. Yuan et al. (2009) obtained yields in the range of $0.06-0.14 \mathrm{~g}$ $\mathrm{COD}_{\mathrm{VFA}} \mathrm{g} \mathrm{COD}^{-1}$ when fermenting WAS from a syntheticwastewater-fed enhanced biological phosphorus-removal process $\left(4.3-13.0 \mathrm{~g} \mathrm{VSS} \mathrm{L}^{-1}\right)$ at $22^{\circ} \mathrm{C}$ with $\mathrm{SRT}=5-10$ days. The higher temperature of $42^{\circ} \mathrm{C}$ used in the present study exhibited a negligible effect on the maximum VFA levels achieved with respect to fermentation at $35^{\circ} \mathrm{C}$, but led to higher VFA yields (results not shown).
PHA accumulation with the liquid fraction of fermented WAS from the pilot plant and biomass enriched with fermented cheese whey permeate proceeded continuously with an almost constant specific storage rate of $330 \mathrm{mg}$ PHAg Xa ${ }^{-1} \mathrm{~h}^{-1}$. A biomass PHA content of $52 \% \mathrm{~g}$ PHA $\mathrm{g} \mathrm{VSS}^{-1}$ was already achieved after 4 hours of accumulation (Figure 2(b)), in which the 3-HV fraction of the produced PHBV was 34\% wt. Biomass growth was relatively low (0.15 g COD Xa $\left._{\text {g }} \mathrm{COD}_{\text {sol }}^{-1}\right)$ and correspondingly, PHA storage was an important mechanism of substrate utilisation, as indicated by a PHA storage yield of $0.48 \mathrm{~g} \mathrm{COD}_{\mathrm{PHA}} \mathrm{g} \mathrm{COD}_{\mathrm{sol}}^{-1}$. Similar yields were obtained in the parallel accumulation test conducted with acetate with similar nutrient levels as feed $\left(0.11 \mathrm{~g} \mathrm{COD}_{\mathrm{Xa}} \mathrm{g} \mathrm{COD}_{\mathrm{sol}}^{-1}\right.$ and $\left.0.51 \mathrm{~g} \mathrm{COD}_{\mathrm{PHB}} \mathrm{g} \mathrm{COD}_{\text {sol }}^{-1}\right)$. After $6 \mathrm{~h}$, the poly(3-hydroxybutyrate) (PHB) fraction of the biomass was almost $42 \%$ (g PHA g VSS ${ }^{-1}$ ), slightly lower than that obtained with the fermented WAS. These PHA accumulation results support the technical feasibility of using the VFA-rich stream from WAS fermentation for PHA production despite its high nutrient content. PHA production at pilot scale using centrate from fermented WAS and biomass enriched on municipal wastewater is currently under development.

\section{Production of value-added PHAs and sludge management}

PHA production integrated with residuals management and environmental protection implies diversion of waste organic 
carbon into a value-added product. This carbon reutilisation may further improve wastewater treatment by reducing waste sludge production, aeration costs and nutrient requirements (Werker et al. 2007). Nevertheless, the scope of the implications of PHA production on municipal wastewater and sludge treatment remains to be fully defined. The PHA accumulation capacity of the biomass selected with municipal wastewater requires optimisation with the whole process in production mode. These aspects together with nutrient and waste management and downstream processing of the PHA-rich biomass are being evaluated in mass and energy balances and life cycle assessments (LCA) as part of Routes (Braguglia et al. 20I2). A first LCA, however, motivates PHA production alongside industrial wastewater treatment from environmental and economical impact perspectives when referenced to pure-culture PHA production and conventional waste management producing biogas (Gurieff \& Lant 2007).

\section{CONCLUSIONS}

The production of biomass with PHA storage capacity was demonstrated both at laboratory and pilot scales based on carbon removal from municipal wastewater treatment. The wastewater is a VFA-poor stream, but a feast-famine approach can nevertheless be applied. The feasibility of using complex, VFA-rich waste streams for PHA accumulation, differing from their use for biomass selection, was demonstrated at laboratory scale, achieving a PHA biomass content of $52 \%$ (g PHA g VSS $^{-1}$ ) after $4 \mathrm{~h}$ fed-batch accumulation. Some level of municipal wastewater treatment (7090\% COD, $15-30 \% \mathrm{~N}, 30-60 \% \mathrm{P}$ removals) could be coupled to PHA production, where VFAs for PHA accumulation could be produced via acidogenic fermentation of primary sludge/WAS. Therefore, waste streams rich in VFAs and nutrients generated during sludge management may be used for PHA production. This study is the first to report pilot-scale results on a PHA production process integrated to actual waste management.

\section{ACKNOWLEDGEMENTS}

The study was partially funded by EU Routes project (Contract No 265156, FP7 2007-2013, THEME [ENV.2010.3.1.1-2] Innovative system solutions for municipal sludge treatment and management) and ANR, programme PRECODD 2008 (project ANR-08-ECOT-017-001).
Technical support for installation and operation logistics of the pilot units by AQUIRIS staff (Brussels North WWTP) is greatly acknowledged.

\section{REFERENCES}

Albuquerque, M. G. E., Eiroa, M., Torres, C., Nunes, B. R. \& Reis, M. A. M. 2007 Strategies for the development of a side stream process for polyhydroxyalkanoate (PHA) production from sugar cane molasses. J. Biotechnol. 130, 411-421.

Bengtsson, S., Werker, A. \& Welander, T. 2008a Production of polyhydroxyalkanoates by glycogen accumulating organisms treating a paper mill wastewater. Water Sci. Technol. 58 (2), 323-330.

Bengtsson, S., Werker, A., Christensson, M. \& Welander, T. 2008b Production of polyhydroxyalkanoates by activated sludge treating a paper mill wastewater. Bioresour. Technol. 99, 509-516.

Bengtsson, S. O. H., Blanchet, E. M., Gurgo e Cirne, M. D. T., Karlsson, C. A. B., Werker, A. G. \& Morgan-Sagastume, F. 2012 Method of treating municipal wastewater and producing biomass with biopolymer production potential. International Patent number WO 2012/023114 A1, 23 February 2012.

Braguglia, C. M., Gianico, A. \& Mininni, G. 2012 ROUTES: innovative solutions for municipal sludge treatment and management. Rev. Environ. Sci. Biotechnol. 11, 11-17.

Coats, E. R., Loge, F. J., Wolcott, M. P., Englund, K. \& McDonald, A. G. 2007 Synthesis of polyhydroxyalkanoates in municipal wastewater treatment. Water Environ. Res. 79 (12), 2396-2403.

De Vegt, O., Werker, A., Fetter, B., Hopman, R., Krins, B. \& Winters, R. 2012 PHA from waste water. Transformation of residual materials and waste water into valuable bioplastics. Bioplastics Mag. 7 (4), 26-28.

Dias, J. M. L., Lemos, P. C., Serafim, L. S., Oliveira, C., Eiroa, M., Albuquerque, M. G. E., Ramos, A. M., Oliveira, R. \& Reis, M. A. M. 2006 Recent advances in polyhydroxyalkanoate production by mixed aerobic cultures: from substrate to the final product. Macromol. Biosci. 6, 885-906.

Dionisi, D., Majone, M., Papa, V. \& Beccari, M. 2004 Biodegradable polymers from organic acids by using activated sludge enriched by aerobic periodic feeding. Biotechnol. Bioeng. 85 (6), 569-579.

Dionisi, D., Carucci, G., Papini, P. M., Riccardi, C. \& Majone, M. 2005 Olive oil mill effluents as a feedstock for production of biodegradable polymer. Water Res. 39, 2076-2084.

Dircks, K., Beun, J. J., van Loosdrecht, M. M. C., Heijnen, J. J. \& Henze, M. 20or Glycogen metabolism in aerobic mixed cultures. Biotechnol. Bioeng. 73 (2), 85-94.

Gurieff, N. B. \& Lant, P. 2007 Comparative life cycle assessment and financial analysis of mixed culture polyhydroxyalkanoate production. Bioresour. Technol. 98, 3393-3403.

Jiang, Y., Marang, L., Tamis, J., van Loosdrecht, M. C. M., Dijkman, H. \& Kleerebezem, R. 2012 Waste to resource: 
converting paper mill wastewater to bioplastic. Water Research. 46, 5517-5530.

Philip, S., Keshavarz, T. \& Roy, I. 2007 Polyhydroxyalkanoates: biodegradable polymers with a range of applications. J. Chem. Technol. Biotechnol. 82, 233-247.

Satoh, H., Iwamoto, Y., Mino, T. \& Matsuo, T. I998 Activated sludge as a possible source of biodegradable plastic. Water Sci. Technol. 38 (2), 103-109.

Serafim, L. S., Lemos, P. C., Albuquerque, M. G. E. \& Reis, M. A. M 2008 Strategies for PHA production by mixed cultures and renewable waste materials. Appl. Microbiol. Biotechnol. 81 (4), 615-628.

Takabatake, H., Satoh, H., Mino, T. \& Matsuo, T. 2002 PHA (polyhydroxyalkanoate) production potential of activated sludge treating wastewater. Water Sci. Technol. 45 (12), 119-126.

Ucisik, A. S. \& Henze, M. 2008 Biological hydrolysis and acidification of sludge under anaerobic conditions: The effect of sludge type and origin on the production and composition of volatile fatty acids. Water Res. 42, 3729-3738.

Valentino, F., Brusca, A. A., Beccari, M., Nuzzo, A., Zanaroli, G. \& Majone, M. 2013 Start up of biological sequencing batch reactor (SBR) and short-term biomass acclimation for polyhydroxyalkanoates production. J. Chem. Technol. Biotechnol. 88 (2), 261-270.
Voltolini, M. 2009 Influence of Feed Composition on Biomass Selection for Polyhydroxyalkanoate Production in Biological Wastewater Treatment. M.Sc. Thesis, Institut für Siedlungswasserbau, Wassergüte- und Abfallwirtschaft, Stuttgart University, Germany.

Werker, A., Bengtsson, S. \& Welander, T. 2007 Biopolymer production from biological waste treatment: activated sludge model evaluation of sludge production and nutrient mass balances for industrial wastewaters. Proceedings of the 4th IWA Leading Edge Technologies. Singapore.

Werker, A. G., Bengtsson, S. O. H. \& Karlsson, C. A. B. 20 II Method for accumulation of polyhydroxyalkanoates in biomass with on-line monitoring for feed rate control and process termination. International Patent number WO 2011/ 070544 A2, 16 June 2011.

Werker, A. G., Johansson, P. S. T., Magnusson, P., Maurer, F. H. J. \& Jannasch, P. 2012 Method for recovery of stabilized polyhydroxyalkanoates from biomass that has been used to treat organic waste. International Patent number WO 2012/ 022998 A1, 23 February 2012.

Yuan, Q., Sparling, R. \& Oleszkiewicz, J. A. 2009 Waste activated sludge fermentation: Effect of solids retention time and biomass concentration. Water Res. 43, 5180-5186. 